\title{
A cidade e o transnacional em Algum lugar, de Paloma Vidal*
}

\author{
Daniela Schrickte Stoll $^{* *}$
}

\section{Resumo}

O artigo analisa o romance Algum lugar (2009), de Paloma Vidal, e pretende perceber, na relação da personagem principal com a cidade de Los Angeles, reflexos de movimentos globais, como imperialismo, imigração e construção de identidades hifenizadas. Seu caminhar pelas avenidas desconhecidas é um gesto muito significativo, porque é uma forma de apropriação, enquanto mulher $e$ imigrante, do espaço excludente da cidade. Objetiva-se, ainda, debater as diferentes experiências das mulheres na diáspora $e$ as possibilidades de um feminismo transnacional.

Palavras-chave: Deslocamentos Transnacionais, Paloma Vidal, Crítica Literária Feminista, Literatura Brasileira Contemporânea.

\footnotetext{
* Recebido em 22 de março de 2019, aceito em 29 de julho de 2020. Este trabalho foi realizado com apoio do CNPq, Conselho Nacional de Desenvolvimento Científico e Tecnológico - Brasil.

** Doutoranda em Literatura no Programa de Pós-Graduação em Literatura da Universidade Federal de Santa Catarina (UFSC), Florianópolis, SC, Brasil. Integrante da comissão editorial da Revista Anuário de Literatura (PPGL/UFSC) e integrante do Núcleo Literatual (Núcleo de Literatura Brasileira Atual - Estudos Feministas e Pós-Coloniais de Narrativas da Contemporaneidade). danielasstoll@yahoo.com.br / http://orcid.org/0000-0001-8843-779X
} 
The City and The Transnational in Algum Lugar, by Paloma Vidal

\begin{abstract}
The article analyzes the novel Algum lugar (2009) by Paloma Vidal to perceive, in the relationship of the main character with the city of Los Angeles, reflections of global movements such as imperialism, immigration, and the construction of hyphenated identities. Her walk along unknown streets is a highly significant gesture, because it is a form of appropriation, as a woman and an immigrant, of the traditionally exclusionary space of the city. The article also discusses the experience of women in the diaspora and possibilities for transnational feminism.
\end{abstract}

Keywords: Transnational movements, Paloma Vidal, Feminist Literary Criticism, Contemporary Brazilian Literature. 
Algum lugaré um romance escrito por Paloma Vidal e publicado em 2009. Nascida em 1975, na Argentina, a escritora, crítica, tradutora e professora mora no Brasil desde os dois anos de idade, primeiro no Rio de Janeiro e atualmente em São Paulo. Ela nunca se naturalizou brasileira, mas se apropriou da condição de estar entre duas línguas e duas culturas. No período de 2002 a 2006, a autora cursou o doutorado na PUC-RJ, com parte da pesquisa feita em Los Angeles, Estados Unidos, onde escreveu Algum lugar (2009), seu primeiro romance. Assim, percebe-se que elementos autobiográficos alimentam o universo ficcional do romance, já que, nele, a personagem principal também nasceu na Argentina, morou no Brasil e se mudou para Los Angeles em função do doutorado.

Algum lugar (2009) é escrito intercalando a narração em primeira, segunda e terceira pessoa. Sua estrutura se assemelha muito a um diário, com trechos de anotações entrecortadas. É um texto que, por vezes, captura notas rápidas, reflexivas, enquanto em outros momentos tenta revirar ou guardar memórias. Tudo isso em meio aos trânsitos e deslocamentos que aparecem inclusive entre os títulos dos três capítulos que compõem o romance ("Los Angeles", "Rio de Janeiro" e "Los Angeles"). O romance situa-se, assim, numa fronteira espacial, cultural e linguística, e, apesar de escrito em português, é repleto de frases em espanhol e em inglês. Algumas semanas depois da chegada aos Estados Unidos, por exemplo, a personagem já começa a usar palavras em inglês em meio a sua escrita: "há poucas pessoas no ônibus, as usual [como de costume]" (Vidal, 2009:28). Mais tarde, ela percebe a necessidade de se expressar em outra língua até consigo mesma: "sinto uma solidão terrível [...] e a necessidade de dizê-lo em outra língua: I feel a terrible solitude" (Vidal, 2009:103).

O enredo enfoca essa personagem principal, da qual não sabemos o nome, que se muda com o marido, chamado de $\mathrm{M}$, para Los Angeles. Nota-se, desde o início, que há uma desconexão entre o casal, sugerida pelo desencontro ainda no aeroporto, ao chegarem na cidade em voos separados. O aeroporto é descrito como um lugar inóspito, que quer expulsar as pessoas dali. No carro, a caminho do quarto que alugaram no centro da cidade, o casal também está distante, e ela abre a janela para se entregar à paisagem:

[abri] a janela para me entregar à paisagem transparente que a cidade oferece, seduzindo-me com uma familiaridade simulada, de casas baixas e palmeiras, lojas e marcas conhecidas, de longas avenidas sob um céu perfeitamente azul. Deixarei que ela me conduza com sua geometria cinematográfica, abandonando a impressão perturbadora do aeroporto com uma sensação de reconhecimento que nesse instante me confortará (Vidal, 2009:17).

Aqui, nesse primeiro contato com a cidade, através da janela do carro, a personagem reconhece uma "familiaridade simulada", paisagens que provavelmente já foram vistas em filmes, séries, notícias e representações - se não aquelas, outras iguais - cenários que são, ao mesmo tempo, reproduções e fabricações de cidade. Naquela "geometria cinematográfica", as lojas e marcas eram conhecidas, como se espera de uma cidade cosmopolita de um país que exporta lojas, marcas, produtos e ideais. Por isso, algumas páginas adiante, a personagem se pergunta: "será nossa viagem mais uma versão do sonho americano?"” (Vidal, 2009:23).

A cidade é, a partir de então, apresentada através do olhar dessa mulher:

Em Los Angeles as avenidas não são exatamente vias de transporte; para se locomover, existem as freeways, que conformam um mapa sobreposto à cidade, um mapa próprio, com suas

\footnotetext{
1 Para Inderpal Grewal (2005), a difusão do "american dream" [o sonho americano] surgiu da necessidade estadunidense de importação de pessoas, porque trabalhadores migrantes custam menos para as corporações, já que podem receber salários menores e não requerem pensões, treinamento ou compromisso a longo prazo. Certos grupos são de maior interesse, como os indianos homens de classe média e alta, falantes de inglês. O discurso e o imaginário do "american way of life" [o modo de vida americano], predominantemente branco, foram, então, transmitidos pela mídia transnacional, e implantaram a ideia de "América" como sinônimo de liberdade, para promover novas formas de internacionalismo assimétrico, poder corporativo e nacionalismo branco. No final do século XX, como consequência dos movimentos sociais, o "american dream" se ligou ao discurso do multiculturalismo e da diversidade para produzir novos consumidores (de gêneros e raças anteriormente marginalizados), mas isso não significou o fim de desigualdades econômicas, apenas criou práticas para permitir que sujeitos se tornassem provisoriamente associados a novas identidades e Estados-nação, ou seja, uma forma de produzir sujeitos nacionais provisórios.
} 
entradas e saídas que guardam uma relação apenas tangencial com o desenho quadriculado, remanescente de uma cidade em que a calçada fazia algum sentido (Vidal, 2009:19).

Há uma dificuldade de se deslocar a pé, em razão da falta de calçadas nas vias principais. Assim, a personagem lê, no guia turístico, que Los Angeles não é uma cidade fácil de compreender. A chave para entendê-la e apreciá-la, segundo consta no guia, seria descartar a noção de que Los Angeles sequer é uma cidade.

Essa dificuldade de se deslocar a pé aparece em vários momentos da narrativa, como neste trecho: "as ruas desertas intimidam, como se ao andar estivéssemos fazendo algo proibido. As distâncias parecem maiores do que são" (Vidal, 2009:36). E neste trecho: "se a cidade fosse outra, poderia andar até lá [até o museu]. É uma linha reta, mas o que significa nessa cidade uma linha reta entre um ponto e outro? Quantos viadutos, avenidas impossíveis de atravessar, ruas sem calçadas haverá até lá?” (Vidal, 2009:38).

A estadunidense Lauren Elkin escreveu, em Flâneuse (2016), sobre as cidades onde as pessoas só se deslocam de carro e as calçadas são inexistentes. Ela se referia aos subúrbios de Long Island, NY, com particularidades que se diferem de Los Angeles, mas a observação sobre a inexistência das calçadas se aplica ao que a personagem de Algum lugar (2009) observou. Segundo Elkin (2016), é chocante ver uma pedestre nessas ruas sem calçada. Se alguém não possui carro, essa pessoa pertence a uma classe inferior, uma "casta de intocáveis" visível apenas quando eles/as estão deslocados/as (out of place), andando na lateral de uma rodovia em que todo mundo passa de carro (Elkin, 2016:22).

Essas pessoas "deslocadas" são o que Zygmunt Bauman (2005), sociólogo polonês, definiu como o "refugo humano" ou os "consumidores falidos"2 (Bauman, 2005), conceitos também trabalhados pelo crítico literário uruguaio Hugo Achugar (2008), e que aqui podem ser pensados com relação a uma escala global: os excluídos são os/as imigrantes, os/as refugiados/as, os/as exilados. Assim, em Algum lugar (2009), a questão não é apenas a mobilidade, mas a dificuldade que a personagem tem de se apropriar daquelas ruas sem calçadas, enquanto sujeito diaspórico a procura de pertencimento. Como metáfora, essa dificuldade pode ser encarada também como representativa do país desenvolvido que não quer enxergar os/as outros/as, os/as imigrantes, as minorias, seus hábitos e culturas: "quem vai me enxergar da velocidade do seu carro?" (Vidal, 2009:39), se pergunta a personagem.

Cabe, nesse momento, situar alguns conceitos importantes para esta discussão, como diáspora, transnacionalidade e imperialismo. Para a brasileira Sandra Goulart Almeida (2015), as diásporas contemporâneas têm relação com o movimento de dispersão de povos, quer seja voluntário ou forçado, com forte impacto político, social e cultural. Trata-se de imigrantes, refugiados/as, exilados/as, aqueles/as que viajam intencionalmente e aqueles/as que são deslocados/as compulsoriamente, repatriados/as, expulsos/as, reassentados/as, tendo em mente, também, todos/as aqueles/as que são confinados/as e imobilizados/as por esse sistema, conforme reforçado por diversos/as autores/as (Massey, 2009; Kaplan, 2000; Vainer, 1998).

\footnotetext{
$2 \mathrm{O}$ argumento de Bauman era que, não apenas a modernidade produziu montanhas de lixo, como também produziu "refugo humano": seres humanos "refugados", "excessivos", que são um efeito colateral do "progresso econômico" e da "construção da ordem" - e cada ordem define algumas parcelas da população como "deslocadas", "inaptas" ou "indesejáveis" (Bauman, 2005:12). Segundo Bauman, "removemos os dejetos da maneira mais radical e efetiva: tornando-os invisíveis, por não olhá-los, e inimagináveis, por não pensarmos neles" (Bauman, 2005:38). A "população excedente" é mais uma variedade do refugo humano. São "baixas colaterais, [...] não intencionais e não planejadas, do progresso econômico" (Bauman, 2005:53). Em obra posterior, Bauman (2009), nomeou esses sujeitos como "supérfluos", porque, segundo ele, não é correto dizer que estejam em excesso, uma vez que sua exclusão agora é permanente. Para o autor, é justamente a irrevogabilidade dessa situação, uma consequência direta da decomposição do Estado social, que transforma os/as excluídos/as em "classes perigosas" (Bauman, 2009:6). Assim, a cidade da contemporaneidade, segundo Achugar (2008), não é mais um lugar onde se vagueia, mas onde as pessoas se deslocam aceleradamente de novidade em novidade. Dessa forma, o presente parece deixar de fora uma grande parte de habitantes do planeta, consistindo numa divisão entre aqueles/as que consomem as novidades e aqueles/as para quem as novidades são apenas espetáculo. É a diferença entre comer e assistir a outro/a comer. Ter a experiência e contemplar a experiência de outro/a (Achugar, 2008)
} 
Inicialmente, a palavra diáspora esteve associada, segundo Almeida (2015), com a dispersão do povo judeu - a diáspora judaica - e, a seguir, com a diáspora dos povos africanos pelo atlântico - denominada diáspora africana ou diáspora negra. Para a estadunidense Patricia Hill Collins (2000), a diáspora negra dispersou muitas pessoas da África para o Caribe, as Américas e a Europa com a finalidade de escravização, por isso, entendimentos sobre a identidade de mulheres afro-caribenhas, afro-americanas e afro-europeias, na contemporaneidade, refletem um padrão específico de dispersão associado com essa imigração forçada a partir do século XVI. De acordo com Collins (2000), a estrutura diaspórica não é normativa, mas existem desafios comuns vivenciados transnacionalmente por essas mulheres (Collins, 2000).

$\mathrm{Na}$ contemporaneidade, o termo é também utilizado por vários campos do conhecimento, como a antropologia, a sociologia, a filosofia, os estudos culturais e literários. Da socióloga Avtar $\mathrm{Brah}^{3}$, por exemplo, é muito conhecida a obra Cartographies of diaspora: contesting identities [Cartografias da diáspora: contestando identidades] (1996), em que se desenvolve a noção de diáspora como um marco interpretativo para analisar questões de ordem econômica, cultural e política relacionadas com formas de migração historicamente específicas. Para Brah (2011), o conceito também se conecta com o terreno das relações sociais, das subjetividades e das identidades, e pode oferecer um contraponto a discursos que propõem noções fixas de origem $e$ pátria. Brah (2011) acredita que a noção de fronteira, como categoria política e analítica, está implícita no conceito de diáspora. Também é central para o argumento da autora a ideia de que o "espaço da diáspora" não é apenas habitado pelos sujeitos das diásporas, mas simultaneamente por aqueles que se pensam "autóctones".

De acordo com Brah (2011), as diásporas costumam ser formadas por muitas viagens a diferentes partes do mundo, cada uma com uma história própria. Assim, a definição de diáspora depende de algumas perguntas, como: que condições socioeconômicas, políticas e culturais marcam as trajetórias dessas viagens? Que regimes de poder se inscrevem em cada deslocamento específico? Como o grupo em deslocamento se situa dentro das relações sociais de classe, gênero, raça e sexualidade no país de destino? Como estas categorias se relacionam na articulação de poder?

$\mathrm{Na}$ contemporaneidade, as novas configurações transnacionais de poder se articulam, segundo a autora, com transformações fundamentais na economia política do capitalismo. $O$ mundo passou a ser caracterizado, por exemplo, pela crescente hegemonia do capital multinacional, pelo impacto das novas tecnologias de produção, distribuição e comunicação, e pela nova divisão internacional do trabalho, que depende extensivamente das mulheres. Também nas diásporas contemporâneas, de acordo com Brah (2011), as mulheres são um segmento crescente em vários locais e em todos os tipos de migração. Isso foi observado ainda por outras autoras (Shohat, 2002; Almeida, 2015), podendo se falar em feminização da globalização e num sujeito gendrado das diásporas contemporâneas (Almeida, 2010).

Dessa forma, as diásporas e os deslocamentos transnacionais aparecem com frequência na literatura contemporânea de autoria feminina, como em Algum lugar (2009), e oferecem possibilidades de questionar estruturas fixas. Por outro lado, evidenciam que, mesmo quando não há barreiras físicas, espaciais ou geográficas, há barreiras de moral, de costumes, de língua, de invisibilizações e de estereótipos. Para Sarah Mahler e Patricia Pessar (2010), que se alinham ao pensamento da geógrafa inglesa Doreen Massey (1994), pode-se pensar em "geografias de poder marcadas por gênero", uma estrutura para analisar a agência dos indivíduos em suas múltiplas posições dentro das hierarquias de poder que operam em diversos espaços. Segundo as autoras, as mulheres têm acesso muito mais limitado a canais de comunicação transnacional do que os homens, porque práticas transnacionais dos Estados-nação reforçam a noção de que cidadania é uma prerrogativa predominantemente masculina. Ou seja, noções patriarcais de pertencimento nacional são transportadas para o contexto transnacional. Por isso, é importante conceituar a ideia de "transnacional" como uma forma de discutir processos sociais, econômicos e culturais que,

\footnotetext{
3 Avtar Brah nasceu na Índia, cresceu em Uganda, estudou nos Estados Unidos e morou e lecionou na Inglaterra.
} 
embora se estendam para além de fronteiras nacionais, estão moldados por práticas políticas $e$ institucionais dos Estados-nação, em contextos nos quais as fronteiras ainda são determinantes.

O conceito de transnacional, assim, se difere do conceito de global e da ideia de globalização, utilizada com frequência e de modo acrítico, sem atentar para um possível imperialismo contemporâneo, com exploração de mão de obra, políticas anti-imigração, xenofobia, tráfico de mulheres, entre outros. Segundo Edward Said (2011), que foi um importante crítico literário palestino e professor nos Estados Unidos, imperialismo é uma palavra e uma ideia controversa, tão carregada de dúvidas e premissas que se torna difícil empregá-la. Há questionamentos a respeito do fim do imperialismo, quando ocorreu, e se a palavra pode de fato ser aplicada aos Estados Unidos. Porém, é possível afirmar que "num nível muito básico, imperialismo significa pensar, colonizar, controlar terras que não são nossas, que estão distantes, que são possuídas e habitadas por outros" (Said, 2011:39).

O imperialismo clássico é associado principalmente à França e à Grã-Bretanha, no século XIX, no entanto, mesmo que esse grande imperialismo clássico tenha chegado ao fim, formalmente, com o desmantelamento das grandes estruturas coloniais após a Segunda Guerra, sua influência cultural, ideológica e política nos territórios das ex-colônias permanece e é perceptível até o presente (Said, 2011:40). Já os Estados Unidos, que utilizaram o discurso do altruísmo e do senso de oportunidade americanos, da prática do bem e da luta pela liberdade, evitaram ser vistos como imperialistas em questões culturais, políticas e históricas, apesar de, desde o início, se fundarem na ideia de um império que se expandiria em território, força e poder (Said, 2011:41-42).

A respeito dos Estados Unidos, Said ainda escreveu:

Os Estados Unidos não são apenas um país de grandes dimensões. São a última superpotência, uma potência de enorme influência, frequentemente intervencionista em todas as partes do mundo. [...] Os Estados Unidos substituíram os grandes impérios anteriores e eles são a força externa dominante na América Central e na América Latina - para mencionar os mais óbvios —, bem como no Oriente Médio, na África e na Ásia (Said, 2011:107, grifo do autor).

Para Said, as políticas estadunidenses ao redor do mundo só podem ser qualificadas como imperialistas. As intervenções militares estadunidenses desde a Segunda Guerra ocorreram e ainda ocorrem em quase todos os continentes, e muitas delas são de grande extensão e complexidade. Tudo isso sob uma falsa aparência de busca pela liberdade e pela democracia, contra as quais Said acreditava que havia espaço para "razoável ceticismo" (Said, 2011:107).

Em Algum lugar (2009), o imperialismo estadunidense aparece sugerido de várias maneiras. A primeira delas, como mencionado, está na possivel metáfora das freeways que se sobrepõem ao traçado da cidade e atropelam a escala humana $e$ as identidades invisibilizadas, como a dos/as imigrantes, que frequentemente se deslocam a pé, na lateral das rodovias sem calçadas. Mas o imperialismo também aparece numa série de referências à guerra no Iraque, que a personagem principal constantemente via nos noticiários da televisão:

Dezenas de canais de vendas oferecem inutilidades. Dezenas de canais de notícias, todos falando da mesma coisa, do mesmo jeito: a guerra do Iraque, nossos mortos no Iraque, como sair do Iraque. A abordagem parece irreal. Iraq War pisca na tela como o letreiro de uma nova estreia (Vidal, 2009:18).

A forma como as notícias de guerras em letreiros luminosos e os canais que anunciam produtos inúteis estão associados pode ser vista como uma crítica que relaciona o imperialismo bélico estadunidense ao pensamento capitalista e consumista. Os letreiros luminosos remetem ao cinema e às estreias em Los Angeles, de onde a personagem assiste ao noticiário. A abordagem leva em conta apenas os "nossos" mortos no Iraque, sem considerar o outro lado. Em trecho posterior, a personagem mostra como a questão territorial é apresentada:

Há uma leitura de mapas, gráficos, fotos aéreas a ser feita. Todo um território demarcado por signos mortíferos a ser reconhecido. Os vales do Tigre e Eufrates são áreas de combate sobre as quais se desenham triângulos, círculos com um ponto no meio, cruzinhas, para marcar os ataques aéreos, a localização da artilharia, as áreas afetadas (Vidal, 2009:30). 
A personagem também comenta a necessidade estadunidense de ser sempre o centro e de que o mundo inteiro esteja atento ao resultado das eleições presidenciais no país. Algo que ela define como uma "voracidade" (Vidal, 2009:51). Depois, fica evidente, no romance, o que Said (2011) chamou de tendências separatistas, essencializantes e dominadoras características do imperialismo:

No rádio, o presidente fala de uma linha divisória. Não entre nações, entre religiões, entre culturas, ele diz. É uma linha que divide a civilização e o terror. Não há terreno neutro, ele repete, entre bem e mal, entre liberdade e escravidão, entre vida e morte. E conclui: they will face their day of justice [eles enfrentarão seu dia de justiça] (Vidal, 2009:88).

A lógica aqui é a mesma que norteou a colonização, criando oposicionismos entre civilização e barbárie para justificar a empreitada colonial. O presidente traça uma linha divisória clara entre o "nós" e o "eles/as", ideia também difundida pelo governo Reagan, em 1986, quando os Estados Unidos atacaram a Líbia em um "golpe contra o terrorismo", segundo o relato de Said (2011): o ataque de Reagan foi programado para ocorrer exatamente no horário nobre do noticiário estadunidense; seguiu-se uma resposta, no mundo muçulmano, que fazia um apelo ao "islã" $e$ gerou uma série de imagens, textos e posturas, no "Ocidente", ressaltando o valor da "nossa" herança judaico-cristã (ocidental, liberal e democrática) em oposição à maldade, à crueldade e à imaturidade da herança "deles/as" (islâmica e do Terceiro Mundo) (Said, 2011:497). Na atualidade, os discursos que marginalizam os/as estrangeiros/as, na "guerra contra o terror", ainda prevalecem. A personagem de Algum lugar reflete tanto sobre esses discursos de guerra quanto sobre a reação da população, que se contradiz: "segundo as pesquisas, mais da metade da população estadunidense acha que a invasão do Iraque foi um erro, porém a maioria das intenções de voto vão para a reeleição do presidente responsável por essa invasão" (Vidal, 2009:106).

Por outro lado, mais do que ver os Estados Unidos apenas como um Estado-nação imperialista, a estadunidense Inderpal Grewal (2005) entende a ideia de "América" como um discurso nacionalista e neoliberal que produziu muitos tipos de agência e de sujeitos, inclusive sujeitos que estão fora das fronteiras territoriais estadunidenses, através da disseminação de tecnologias neoliberais por múltiplos canais, bem como da criação de redes de conhecimento e poder, cosmopolita e global, que atravessam e rearticulam fronteiras nacionais. Grewal (2005) se interessa pela relação entre geopolítica e biopoder no que diz respeito à produção de corpos $e$ sujeitos gendrados e racializados. Para ela, as conectividades transnacionais criaram sujeitos, tecnologias e práticas éticas de diferentes tipos, bem como criaram conceitos de "global" $e$ "universal" como sendo conectados e dominantes. Apenas determinados sujeitos foram capazes de se apropriar desses discursos neoliberais e desses conhecimentos, de acordo com gênero, classe e raça.

É nesse cenário que a personagem do romance se encontra e com o qual tenta criar alguma conexão. Sendo uma imigrante, ela oscila entre o estranhamento pela cidade que não a acolhe e o desejo de pertencimento. Além dela, os/as personagens do romance são majoritariamente imigrantes: o amigo chileno que empresta o carro ao casal, a colega colombiana que se torna vizinha, a colega coreana na universidade (Luci), o médico argentino, o professor argentino (Pablo), as alunas peruanas, a namorada equatoriana do porteiro do prédio. Por isso, a personagem principal afirma: "se depender de Los Angeles, nosso inglês permanecerá eternamente como é: uma língua básica, latinizada, de passagem" (Vidal, 2009:21).

De acordo com dados da International Organization for Migration, em 2015, havia mais de 46 milhões de imigrantes nos Estados Unidos, o equivalente a $14,49 \%$ da população residente no país naquele ano (IOM, 2015). Além dos imigrantes com visto, como a personagem do romance, estima-se que, entre o México e os Estados Unidos, todos os anos, 150 mil imigrantes ilegais ${ }^{4}$

\footnotetext{
4 Segundo a IOM (2017), o risco envolvido na migração ilegal é frequentemente gendrado. Além dos riscos das travessias, as mulheres ainda estão expostas às violências de gênero, em todas as etapas do processo, não importando a idade ou o estado civil. A discriminação é dupla: relativa ao gênero e à condição ilegal, o que as torna mais expostas ao risco de abusos e de morte. Mulheres são frequentemente forçadas a "oferecer serviços sexuais" quando negociam a travessia, caso reportado por $60 \%$ das mulheres que viajaram pelo México em 2010 . Há registros de mulheres que foram
} 
cruzam a fronteira em direção ao norte. A maioria desses/as imigrantes é proveniente das Américas Central e do Sul, mas, em menor grau, há aqueles/as que vêm de outras regiões como a Ásia e a África.

O estado da Califórnia, onde fica a cidade de Los Angeles, cenário do romance Algum lugar (2009), faz fronteira com o México, esse país que se tornou uma "rota de entrada" aos Estados Unidos. A relação com o país vizinho, nessa "zona de contato" (Pratt, 1999), se mostra nos nomes das ruas, em espanhol, assim como no nome da própria cidade e no que a personagem de Algum lugar (2009) chama de "arquitetura com sotaque":

Foi aqui que tudo começou, diz o guia; é aqui o centro da cidade sem centro. El Pueblo de Nuestra Señora la Reina de Los Angeles del Río Porciúncula foi fundado, no final do século XVIII, nas quadras que hoje se chamam "The Plaza". Pouco a pouco a cidade e a riqueza foram se dirigindo para o mar e sobraram ali alguns simulacros de origem, uma rua, uma praça, alguns mexicanos que tentam tirar proveito dessa pré-história e da força da língua, marca que não se apaga. Ali, como em qualquer outro canto da cidade, o espanhol dá provas de sua resistência: La Placita, Sepulveda House, Avila Adobe, Merced Theater. Uma arquitetura com sotaque, por mais que quase nada tenha sobrevivido. Tudo derrubado para que no seu lugar surja algo maior, mais alto, mais imponente. A vontade faraônica está por toda parte, nas supercatedrais, nos megamuseus, nos arranha-céus (Vidal, 2009:79).

Essa passagem demonstra uma paisagem cultural marcada pelo hibridismo. É um lugar, um espaço físico concreto, que apresenta, em caráter local, reflexos de movimentações globais. Essas movimentações são as disputas do passado, por território, que serão explicadas em seguida, mas também reflexos da globalização neoliberal contemporânea, das relações entre os mercados estadunidense e mexicano, das migrações, das trocas de imagens e símbolos através da mídia global (Connel; Pierce, 2015), entre outros fatores.

A fronteira entre o México e os Estados Unidos, com $3.141 \mathrm{~km}$, é a mais transitada em todo o mundo, o que faz com que o México tenha estreita ligação econômica, política e social com a migração, conforme observam os pesquisadores mexicanos Thomas Weiss e Pedro Chaltelt (2011). Nessa fronteira, o presidente estadunidense Donald Trump propôs, em 2016, a construção de um muro que possa barrar a entrada ${ }^{5}$ dos/as imigrantes, maior e mais resistente do que os muros que já existem em alguns trechos, como na fronteira entre Tijuana e San Diego, por exemplo, onde foram colocadas cruzes em memória dos/as migrantes mortos/as na tentativa de atravessar em direção aos Estados Unidos.

Os imigrantes que habitam nos Estados Unidos, legal ou ilegalmente, além de facilmente identificáveis como as pessoas sem carro, andando na lateral das ruas sem calçadas (Elkin, 2016), também se percebem segregados em bairros periféricos, como aparece em Algum lugar (2009): "descendo em direção ao sul, longe da praia, onde moram os mexicanos, os negros e, mais recentemente, os asiáticos, [nota-se] o abandono" (Vidal, 2009:92).

No entanto, a relação entre Estados Unidos e México não se resume aos imigrantes e aos trânsitos pela fronteira, porque diz respeito também às disputas por território no passado. Nesse sentido, a escritora e teórica cultural chicana ${ }^{6}$ Gloria Anzaldúa (1987) contribuiu muito para o

mortas ao resistir à violência sexual e ao estupro. Além disso, as mulheres também estão mais expostas ao risco de tráfico de pessoas (IOM, 2017). Os dados apresentados são da Anistia Internacional, segundo a IOM.

5 Diante da quantidade de mexicanos/as impedidos/as de entrar nos Estados Unidos ou expulsos/as de lá, Carlos Vainer (1998), economista e sociólogo brasileiro, contestou o pressuposto ideológico que sustenta o conceito universal da teoria migratória, ancorado na "famosa" liberdade de ir e vir, "representada como conquista fundamental, e verdadeiro mito de origem, da sociedade burguesa" (Vainer, 1998:820).

${ }^{6}$ Chicanos são pessoas nascidas nos Estados Unidos com ascendência mexicana. É uma identidade de fronteira - não apenas geográfica, mas também linguística e cultural, utilizada como forma de afirmação política. Essas pessoas enfrentam uma série de dificuldades relacionadas com a língua e a cultura: não são espanhóis/olas, nem vivem em um país cuja primeira língua seja o espanhol, vivem nos Estados Unidos e não se identificam nem com o espanhol formal, nem com o inglês formal. O recurso encontrado por eles/as foi a criação de línguas próprias, com as quais conseguem conectar suas identidades, comunicar seus valores e ser verdadeiros/as consigo mesmos/as. Línguas que não são nem espanhol, nem inglês. No entanto, são línguas mal-vistas por todos os lados, como línguas racializadas (Anzaldúa, 1987:55). Para Anzaldúa, que é chicana, a fronteira entre os Estados Unidos e o México é "uma ferida aberta onde o Terceiro Mundo 
entendimento das disputas entre os Estados Unidos e o México (sejam disputas territoriais, culturais, políticas, étnicas ou linguísticas). Segundo a autora, em 1846, os Estados Unidos incitaram o México à guerra, tomando metade da sua nação, o que hoje corresponde ao Texas, ao New Mexico, ao Arizona, ao Colorado e à Califórnia. As batalhas já ocorriam no território desde o século XIX, quando ingleses/as migraram ilegalmente para o Texas, que na época pertencia ao México, $e$ gradualmente forçaram os/as tejanos/as a sair de suas terras através de uma série de atrocidades. Na batalha chamada de Batle of Alamo, o México lutou para recuperar suas terras, o que se tornou, para os/as brancos/as, símbolo da covardia e vileza mexicanas, justificando assim a abordagem imperialista que vieram a ter e ainda têm (Anzaldúa, 1987:6).

De acordo com a autora, os/as mexicanos/as que ficaram do lado da fronteira que passou a ser estadunidense sofreram ameaças e foram ignorados/as pela justiça e pelos governos oficiais. Assim, passaram a protestar e organizar retaliações como forma de resistência. Ocorreram então linchamentos de chicanos/as e a guerra entre as etnias se consolidou. Atualmente, o México é quase totalmente dependente do mercado estadunidense, que exporta também valores culturais para o país vizinho (Anzaldúa, 1987:8-10). Aqueles/as mexicanos/as que, na contemporaneidade, cruzam as fronteiras em direção aos Estados Unidos encontram-se em meio a anos de preconceito, na berlinda entre "serem tratados como criminosos e terem o que comer, entre a resistência e a deportação, os refugiados ilegais são algumas das pessoas mais pobres e mais exploradas dos Estados Unidos" (Anzaldúa, 1987:12).

A passagem citada, em que a personagem de Algum lugar (2009) diz que alguns mexicanos tentam "tirar proveito dessa pré-história", em determinados espaços, para ganhar algum dinheiro, pode denotar que ela mesma estava imersa na cultura estadunidense que oprime e inferioriza as pessoas mexicanas, ignorando a história das batalhas naquele território. Ignora ainda o que Avtar Brah (2011) chamou de "o paradoxo do trabalhador indocumentado", que expõe como os Estados Unidos necessitam de trabalhadores/as mexicanos/as para realizar trabalho mal remunerado, normalmente nos setores mais baixos da economia, enquanto, ao mesmo tempo, marginalizam $e$ criminalizam os/as mesmos/as, que são confrontados/as com racismo, no dia a dia, ou obrigados/as a se fazerem invisiveis (Brah, 2011:232). Por fim, a personagem de Algum lugar (2009) talvez ignore também o quanto desse preconceito se estende até ela própria, uma imigrante "latina".

Apesar de estudar na universidade, o que poderia sugerir certo prestígio e distanciamento dos problemas enfrentados pelos/as imigrantes ilegais, a personagem praticamente não faz amizades ou conhecidos/as entre os/as estadunidenses. Isso reafirma o argumento de que ela própria é vista e tratada como imigrante, com todos os estereótipos que a identidade carrega. Ela se sente isolada, numa cidade que a "massacra diariamente" e a faz pagar por seu desconhecimento espacial. Para lutar contra isso, a personagem tenta criar um circuito doméstico:

Percebo que estou querendo criar para mim um circuito doméstico na cidade, contrariando a evidência de que o meu bairro não é um bairro. Comemoro cada nova descoberta como uma pequena vitória contra a dispersão da cidade. Já sei onde encontrar uma tinturaria, um mecânico, uma relojoaria; a quatro quadras de casa, uma papelaria; numa rua atrás do supermercado, um vidraceiro; descendo a grande avenida à esquerda, uma loja de fantasias. Uma loja de fantasias? Para quê você quer uma loja de fantasias?, M pergunta. Não importa. O que importa é a descoberta, como se a promessa de uma necessidade sanada pudesse me resgatar provisoriamente de meu estado de isolamento. Se precisar, já sei onde encontrar. É um caminho que se desenha entre dois pontos que antes não tinham conexão alguma (Vidal, 2009:32).

encontra o Primeiro e sangra" (Anzaldúa, 1987:3). Viver na fronteira é um estado constante de transição, nesse lugar que tenta definir o "eles/as" e o "nós". É também um estado de transgressão: as mestizas, como as pessoas queer e outras transgressoras, cruzam as fronteiras do que é tido como "normal" (Anzaldúa, 1987:3).

7 Nascidos no Texas de ascendência Mexicana.

8 "Caught between being treated as criminals and being able to eat, between resistance and deportation, the ilegal refugees are some of the poorest and the most exploited of any people in the U.S.". 
Ela trava uma luta constante contra o sentimento de desterritorialização, que acaba refletida numa luta contra a própria cidade, contra a constatação inicial de que "a desconexão prevalece" (Vidal, 2009:23). É também uma luta contra a impressão de que ela não consegue encontrar o mesmo lugar duas vezes, como percebe-se nesse trecho: "no fim de semana seguinte, tentamos [ela $e$ o marido] chegar àquela mesma entrada do parque, mas ficamos presos no labirinto de ruas $e$ acabamos voltando decepcionados para casa" (Vidal, 2009:88).

O momento mais emblemático dessa luta contra a cidade é a tentativa de ir até o museu Getty Center, que ela deveria alcançar se seguisse uma linha reta a partir de casa:

Vou subindo a Sepúlveda Boulevard em direção ao norte. [...] O sol esquenta bastante, apesar da época do ano. Estou de casaco e calça de um moletom bem grosso, [...]. Me arrependo de ter saído vestida desse jeito. [...] [Mas] não posso gastar energia com recriminações. Preciso dela para caminhar ao lado da 405, sem sombra, sem calçada, com carros passando a uma proximidade alarmante. Piso firme no chão e intensifico a marcha, como se obedecesse a uma ordem externa.

Mais algumas dezenas de metros e já tenho certeza de estar colocando a mim mesma num desafio inútil, personificando a cidade, transformando-a num ser que preciso conquistar, fixando-a na imagem de um modo de vida ao qual eu deveria resistir, apesar de admitir que sou totalmente capaz de me adaptar a ele. Provavelmente por isso mesmo, tendo entendido que afinal de contas é muito fácil fazer parte, instalada numa rotina cronometrada, de repente me sinto impelida a me contrapor através dessa luta corporal que se tornou a caminhada em direção ao Getty Center; uma luta que vou perder, com meu ânimo já esvaziado e minhas energias se esgotando. A cada passo desanimo mais um pouco, não tanto pelo caminho percorrido mas por sentir que tudo à minha volta me é hostil. Não devia estar ali. Continuo por mais alguns metros, até uma encruzilhada, e me sento no meio-fio (Vidal, 2009:39).

Seu raciocínio demonstra a contradição e o medo de acabar se adaptando facilmente ao modo de vida dos/as moradores/as de Los Angeles (indiferentes em seus carros velozes? Imersos/as na rotina? Só mais outras versões do sonho americano?), enquanto acha que deveria resistir e continuar reivindicando seu estranhamento no olhar (sua identidade de estrangeira, de imigrante). Seus medos são comuns em narrativas da diáspora, segundo Sandra Goulart Almeida (2015): por um lado os/as habitantes da cidade têm medo da ameaça estrangeira e, por outro, os sujeitos em trânsito têm medo de "serem aculturados e devorados [...] por um sistema hegemônico que divide a cidade cosmopolita com base no padrão dicotômico 'nós e eles'" (Almeida, 2015:171).

A sugestão de ir ao museu partiu da mãe da personagem, numa conversa por telefone, e a tentativa de ir, como a personagem reconhece, era uma forma de se conectar com a mãe: "encontrar um caminho na cidade que se conectasse com aquela voz [da mãe]" (Vidal, 2009:40). A procura por familiaridade fica evidente a partir dessa afirmação.

Além disso, a personagem busca se encontrar nos espaços da cidade. Desconectada do marido, que se isola em casa, ela pensa da seguinte forma: "se não tenho um espaço meu do lado de fora, meus pensamentos não me pertencem" (Vidal, 2009:21). Atitudes como a tentativa de se tornar uma tree watcher, observadora de árvores, demonstram essa necessidade de se apropriar dos espaços públicos. Quando ela decide ir ao evento Cemetery screenings, em Hollywood, não tem coragem de admitir para os/as outros/as, mas confessa para si mesma que o motivo de querer ir era "a vontade de ser parte de alguma coisa que parecia tão própria da cidade" (Vidal, 2009:73). Percebe-se como a contradição entre estranhamento e necessidade de pertencimento é característica das movimentações da diáspora, ainda que assuma diferentes contornos dependendo dos sujeitos e de suas posições no contexto histórico e geopolítico. Para o teórico cultural e sociólogo jamaicano Stuart Hall (2006), as pessoas que foram dispersadas de sua terra natal

são obrigadas a negociar com as novas culturas em que vivem, sem simplesmente serem assimiladas por elas e sem perder completamente suas identidades. Elas carregam os traços das culturas, das tradições, das linguagens e das histórias particulares pelas quais foram marcadas. A diferença é que elas não são e nunca serão unificadas no velho sentido, porque elas são, irrevogavelmente, o produto de várias histórias e culturas interconectadas, pertencem a uma e, ao mesmo tempo, a várias "casas" (e não a uma "casa" particular) (Hall, 2006:24) 
A coreana Luci é quem ajuda a personagem de Algum lugar (2009) a se familiarizar com a cidade, apesar de ser também imigrante e passar por seu próprio processo de negociação com a nova cultura. A relação entre elas é repleta de desencontros. Ambas falam espanhol como segunda língua, estudam os mesmos temas na universidade em que se conhecem, nos Estados Unidos, porém enfrentam dificuldades de comunicação:

Como nas conversas que temos sobre literatura, o que ela pensa acaba não ficando claro para mim. Não se trata exatamente de ambiguidade, pois ela parece estar bem certa do que acredita. É algo nas explicações que gera uma incompreensão, algo no encontro entre o espanhol dela e o meu, uma espécie de curto-circuito (Vidal, 2009:69-70).

Há uma situação em que a personagem convida Luci para ir ao bairro chinatown e a colega responde que só sabe ir até koreatown (Vidal, 2009:67). Esse é um dos desencontros entre elas e é também um exemplo do que a crítica iraquiana Ella Shohat (2002) explicou da seguinte forma: "as diversas culturas da Ásia são condensadas em um rótulo homogeneizador que apaga suas diferenças e complexidades: daí a típica confusão entre japoneses e chineses" (Shohat, 2002:103). A personagem principal presumiu que Luci gostaria do convite ou que saberia ir até chinatown, já que era asiática, mas o bairro chinês não significava nada para Luci, que era coreana. A isso, Shohat se refere como uma "síndrome de confusão asiática", a ideia de que todos/as "eles/as" são iguais. Segundo ela, até o "visual asiático" pode ser enganoso no contexto estadunidense, levando asiáticos/as que já habitam o país há gerações a serem vistos/as como "sempre estrangeiros" (Shohat, 2002:106).

Conforme Shohat argumenta, um dos pontos centrais do cruzamento de fronteiras tem relação com a classificação $e$ a catalogação de identidades. Os/as norte-africanos/as $e$ médioorientais também são vistos/as como "eternos/as estrangeiros/as", sempre "de lá", ainda que muitas pessoas do Norte da África e do Oriente Médio tenham migrado no final do século XIX. Os/as chicanos/as, como Anzaldúa, que nunca cruzaram a fronteira rumo aos Estados Unidos (foram as fronteiras que mudaram), são sempre tratados/as pela mídia como essencialmente de fora, também "de lá". Por outro lado, Shohat aponta a ironia da celebração em torno da figura de Cristóvão Colombo, "o primeiro estrangeiro ilegal", tratando-o como um descobridor, "enquanto mexicanos nativos são vistos como aqueles que se infiltraram [em] uma fronteira de arame farpado, fronteira que na verdade divide sua terra natal" (Shohat, 2002:103). Já os/as indígenas em solo estadunidense, como os/as cherokees, os/as net perces e os/as modocs são tratados/as como "daqui", porém sentem-se como refugiados/as internos/as. Para Shohat, o nacionalismo dos Estados Unidos não permite uma narrativa de todas essas identidades, tampouco daqueles/as deslocados/as pela "devastadora política global norte-americana" (Shohat, 2002:103).

Segundo a autora, espera-se que as pessoas hifenizadas pela diáspora (afro-americanos/as, por exemplo) adotem apenas um hífen simples. No entanto, os sucessivos deslocamentos coloniais $e$ pós-coloniais, que se somam ainda mais nas diásporas contemporâneas, "pressionam consideravelmente esse já carregado e sobredeterminado hífen simples" (Shohat, 2002:107).

Assim, Shohat afirma que

cada cadeia de hífens implica uma história complicada de identidades aglomeradas e pertencimentos fragmentados, enquanto deslocamentos múltiplos geram "destilações" diferentes da identidade imigrante. Mas frequentemente o país "hospedeiro" reconhece somente um elo da corrente, e esse elo, carimbado como "real", nos diz menos sobre o imigrante do que sobre o imaginário geopolítico do hospedeiro (Shohat, 2002:107).

As duas personagens mencionadas de Algum lugar, Luci e a narradora, estariam situadas, então, entre os hífens argentina-brasileira-estadunidense e coreana-colombiana-estadunidense. Suas situações também estão relacionadas com um hífen entre ser-estar, já que a condição de estadunidense pode ser temporária, marcada para terminar com o doutorado, assim como colombiana foi uma identidade em trânsito. Para Grewal (2005), a ideia de nacionalismo se tornou muito menos relacionada com território do que anteriormente, e essas múltiplas afiliações podem ser, por vezes, conflituosas. Como consequência disso, o processo pelo qual imigrantes $e$ 
refugiados/as narram a si mesmos em solo estadunidense não é simples e tampouco adequadamente descrito pela ideia de assimilação ou aculturação.

Nesse sentido, Shohat (2002) acredita que olhar para as vidas de diversos/as imigrantes significa desafiar as limitações da categorização de identidades. Da mesma forma, ela aponta como crucial que as feministas multiculturais examinem a "interação multilateral de diversas comunidades" (Shohat, 2002:102), uma vez que mesmo dentro de um espaço feminista multicultural as identidades podem ser "interpretadas e reconhecidas de forma equivocada" (Shohat, 2002:108). Para a autora,

definições raciais, hierarquias étnicas, identidades de gênero $e$ formas de pertencimento ligadas ao sexo são conjunturais e historicamente situadas, sempre se alterando, transmudando-se através de histórias e geografias. Elas explodem e implodem uma narrativa unificada daquilo que constitui as identificações e filiações "raciais", "nacionais" e "sexuais" (Shohat, 2002:108).

Avtar Brah (2011) argumenta da mesma maneira: a autora afirma que o destino das pessoas está diretamente ligado ao sistema econômico global, porém sua posição exata depende de vários fatores: gênero, classe, cor, etnia, casta, idade, sexualidade e o país em que se vive, com uma sociedade rica ou com uma indústria avançada ou não. Segundo a autora, a interseccionalidade desses fatores é uma dinâmica formativa dentro dos processos de reestruturação globais, nacionais, regionais e locais. Portanto, "isso significa que, onde as diferentes diásporas se entrecruzam - a africana, a judia, a irlandesa, a asiática, entre outras -, se faz necessário examinar como esses grupos estão construídos de forma similar ou diferente em relação aos outros" (Brah, 2011:221, tradução minha).

Cabe ressaltar que o termo "interseccionalidade" foi cunhado pela estudiosa e militante afroamericana Kimberlé Crenshaw, em 1989, embora já fosse utilizado por movimentos políticos e por acadêmicas feministas negras antes disso - a base para o conceito já estava anunciada no discurso de Sojourner Truth, uma mulher escravizada nos Estados Unidos, intitulado "Não sou uma mulher?", em 1852. Para Avtar Brah e Ann Phoenix (2017), a interseccionalidade é

um conceito que denota os efeitos complexos, irredutíveis, variados e variáveis que advêm quando eixos de diferenciação múltiplos - econômico, político, cultural, físico, subjetivo e experiencial -se interseccionam em contextos historicamente específicos. O conceito ressalta que as diferentes dimensões da vida social não podem ser separadas em vertentes discretas $e$ puras (Brah; Phoenix, 2017:662).

Por sua vez, a alemã Ina Kerner defende que as categorias gênero, raça e classe se interseccionam de diferentes maneiras em diferentes contextos, por isso é importante analisar as formas como as opressões ocorrem em caráter epistêmico (discursos e saberes, símbolos e imagens), institucional (arranjos institucionais que produzem formas estruturais de hierarquização $e$ discriminação) e pessoal (atitudes, posicionamentos individuais, identidade, subjetividade, interações pessoais) (Kerner, 2012). Isso porque as formas de opressão são fenômenos complexos de poder que não podem ser submetidos a uma análise simplista, devendo ser analisadas a partir de suas semelhanças, suas diferenças, seus acoplamentos e suas intersecções (Kerner, 2012).

Questões relativas ao feminismo, para Brah (2011), também não podem se situar sem uma referência a esse contexto internacional. Segundo a autora, os feminismos construíram reflexões importantes sobre espaço, localização, desterritorialização e deslocamento, de onde surgiu a noção de "política de localização", ou seja, uma localização da dispersão, um habitar simultâneo de espaços, uma movimentação através de barreiras culturais, religiosas e linguísticas mutantes, por meio de viagens através de fronteiras geográficas e psíquicas (Brah, 2011:236). Existem, assim, diferentes espaços de fronteiras, que podem constituir variadas consciências, dependendo do investimento psíquico na manutenção ou na erosão do status quo, por isso a importância de

\footnotetext{
9 "Lo que esto significa es que alli donde distintas diásporas se entrecruzan - la africana, la judía, la irlandesa, la asiática y demás - se hace necesario examinar cómo estos grupos están construidos de forma similar o diferente los unos respecto a los otros".
} 
associar os estudos sobre as fronteiras com os estudos pós-coloniais, os estudos LGBTQI+, entre outros (Brah, 2011).

Inderpal Grewal (2005), no entanto, critica a forma como certos tipos específicos de feminismo foram poderosos o suficiente para se mover por conectividades transnacionais através do conceito de escolha, central tanto para o feminismo quanto para práticas de consumo neoliberal. Assim, ela analisa a imbricação do feminismo com a cultura do consumo e reflete sobre conhecimentos cosmopolitas (acadêmicos e ativistas) que não escapam das condições neoliberais. Grewal (2005) argumenta, partindo da obra The birth of biopolitics [Nascimento da Biopolítica] (1979), do filósofo francês Michel Foucault, que os processos de mercantilização se estenderam para os movimentos sociais e os discursos feministas no final do século XX. Por isso, a autora se propõe a pensar a relação entre biopolítica e geopolítica. Para Grewal (2005), a produção de sujeitos (étnicos, multiculturais, transnacionais) foi um processo repleto de conflitos e contradições, assim como nas diásporas, nos nacionalismos e no feminismo "global", entre outras formações.

Pelo que foi exposto aqui, através da argumentação de Inderpal Grewal, Avtar Brah, Ella Shohat e Gloria Anzaldúa, chega-se à conclusão de que não é possível universalizar a experiência da mulher na diáspora, conforme apontado também por Sandra Almeida (2010). Pelo contrário, Brah (2011) acredita que diante da cumplicidade entre o discurso do universalismo e os projetos hegemônicos do imperialismo, pode ser útil adotar a ideia de identificações transculturais (Brah, 2011:120). Através da literatura, Almeida (2010) acredita que seria possível "refletir sobre e problematizar [...] o papel das mulheres no atual cenário social e geopolítico e a consequente feminização da globalização, do cosmopolitismo e da diáspora contemporânea" (Almeida, 2010:20). Sua proposta é procurar um "encontro dialógico das diferenças", conceito que também vem de Ella Shohat (2004).

Em conclusão, na análise do romance, foi possível perceber que, para a personagem principal - que desfrutava do privilégio de cursar doutorado nos Estados Unidos, onde morava legalmente as fronteiras e os muros eram as longas freeways que ela não conseguia cruzar a pé, denunciando seu pertencimento àquela "casta de intocáveis" sem carro (Elkin, 2016), à qual pertenciam as pessoas pobres e os/as imigrantes. Foi através dos deslocamentos dela, à procura de encontrar seu lugar na cidade, que as questões relativas ao imperialismo estadunidense, à imigração e à construção de identidades hifenizadas foram observadas.

Em Algum lugar (2009), a "arquitetura com sotaque" entre México e Estados Unidos confirmou a presença de marcas simbólicas e representativas, na escala do tecido urbano, de estruturas imperialistas em escalas que ultrapassam a cidade, assim como de resistências que comprovam a força da língua. Notou-se, assim, momentos em que o global foi percebido no local, o que aponta para o fato de os aspectos globais e locais das condições contemporâneas não poderem ser relacionados apenas de modo secundário e ocasional.

Da mesma forma, conclui-se que as narrativas de autoria feminina sobre deslocamentos transnacionais, como Algum lugar (2009), trazem uma possibilidade importante de diálogo com as teorias feministas contemporâneas, que procuram observar contextos históricos e geopolíticos como ponto de partida para reflexões a respeito de identidades e cartografias, mobilidades e imobilidades, interseccionalidades e transnacionalidades.

\section{Referências bibliográficas}

ACHUGAR, Hugo. Culpas y memorias em las modernidades locales: balbuceos fragmentarios so pretexto de "el flâneur" de Walter Benjamin. Revista eletrónica de estudios filológicos (16), s.p., dezembro 2008. [https://www.um.es/tonosdigital/ znum16/secciones/estudios-1.htm - acesso em julho de 2017].

ALMEIDA, Sandra G. Mulheres tão diferentes que éramos: a escritora contemporânea $e$ as narrativas cosmopolitas na aldeia global. In: DALCASTAGNE, Regina; LEAL, Virgínia (org.). Deslocamentos de gênero na narrativa brasileira contemporânea. São Paulo, Horizonte, 2010, pp.12-22.

Cartografias contemporâneas. espaço, corpo, escrita. Rio de Janeiro, 7Letras, 2015.

ANZALDÚA, Gloria. Borderlands/La Frontera: the new mestiza consciousness. San Francisco, Aunt Lute Press, 1987. 
BAUMAN, Zygmunt. Vidas desperdiçadas. Rio de Janeiro, Zahar, 2005.Tradução de Carlos Alberto Medeiros. Confiança e medo na cidade. Rio de Janeiro, Zahar. 2009. E-book. Tradução de Eliana Aguiar.

BRAH, Avtar. Cartografías de la diáspora: identidades en cuestión. Madrid, Traficantes de sueños, 2011 [1996].

BRAH, Avtar; PHOENIX, Ann. Não sou uma mulher? Revisitando a interseccionalidade [2004]. Tradução de Claudia Santos Mayer e Matias Corbett Garcez. In: BRANDÃO, Izabel; CAVALCANTI, Ildney; COSTA, Cláudia de Lima; LIMA, Ana Cecília Acioli (org.). Traduçóes da cultura: perspectivas críticas feministas (1970-2010). Florianópolis, Editora da UFSC, 2017, pp.661-684.

COLLINS, Patricia Hill. Black feminist thought. Knowledge, Consciousness, and the Politics of Empowerment. New York, London, Routledge, 2000.

CONNEL, Raewyn; PEARSE, Rebecca. Gênero: uma perspectiva global. São Paulo, nVersos, 2015.Tradução e revisão técnica: Marília Moschkovich.

ELKIN, Lauren. Flâneuse: women walk the city in Paris, New York, Tokyo, Venice and London. New York, Farrar, Straus and Giroux, 2016. E-book.

GREWAL, Inderpal. Transnational America: feminisms, diasporas, neoliberalisms. Londres, Duke University Press, 2005.

HALL, Stuart. Da diáspora: identidades e mediações culturais. Belo Horizonte, Editora UFMG, 2006. $1^{\text {a }}$ reimpressão revista. Tradução de Adelaine La Guardia Resende; Ana Carolina Escosteguy et al.

INTERNATIONAL Organization for Migration. World migration. 2015 [https://www.iom.int/world-migration acesso em outubro de 2017].

Fatal journeys. 2017 [http://publications.iom. int/system/files/pdf/fatal_journeys_volume_3_part_1.pdf - acesso em outubro de 2017].

KAPLAN, Caren. Questions of travel: postmodern discourses of displacements. Durham, Duke University Press, 2000. E-book.

KERNER, Ina. Tudo é interseccional? Sobre a relação entre sexismo e racismo. Tradução de Bianca Tavolari. Novos estudos - CEBRAP (93), 2012, pp.45-58 [http://www.scielo.br/pdf/nec/n93/ n93a05.pdf - acesso novembro de 2017].

MAHLER, Sarah J.; PESSAR, Patricia R. Gendered Geographies of Power: Analyzing Gender Across Transnational Spaces. Identities: Global Studies in Culture and Power (7:4), 2001, pp.441-459.

MASSEY, Doreen. Space, place and gender. Minneapolis, University of Minnesota Press, 2009 [1994].

PRATT, Mary Louise. A crítica na zona de contato: nação e comunidade fora de foco. Travessia (38), 1999, pp.7-29.

SAID, Edward. Cultura e imperialismo. São Paulo, Companhia das Letras, 2011 [1993]. Tradução de Denise Bottmann.

SHOHAT, Ella. A vinda para a América: reflexões sobre perda de cabelos e de memória. Revista Estudos Feministas (10:1), 2002, pp.99-117 [http://www.scielo.br/pdf/ref/v10n1/ 11631 - acesso em outubro de 2017].

VAINER, Carlos. Deslocamentos compulsórios, restrições à livre circulação: elementos para um reconhecimento teórico da violência como fator migratório. In: Encontro Nacional de Estudos Populacionais da ABEP, 11, 1998, Caxambu, MG. Anais... Belo Horizonte, ABEP, 1998, pp.819-835.

VIDAL, Paloma. Algum lugar. Rio de Janeiro, 7Letras, 2009.

WEISS, Thomas; CHALTELT, Pedro. México: public policies benefiting migrants. Cidade do México, Organización Internacional para las Migraciones Misión México, 2011 [http://publications.iom.int/system/files/pdf/oim_pp_en.pdf - acesso em outubro de 2017]. 